\title{
The economic burden of schizophrenia in Malaysia
}

This article was published in the following Dove Press journal:

Neuropsychiatric Disease and Treatment

28 July 2017

Number of times this article has been viewed

\author{
Siew Li Teoh' \\ Huey Yi Chong' \\ Salina Abdul Aziz ${ }^{2}$ \\ Norliza Chemi ${ }^{2}$ \\ Abdul Razak Othman ${ }^{2}$ \\ Nurzuriana Md Zaki \\ Possatorn Vanichkulpitak ${ }^{3}$ \\ Nathorn \\ Chaiyakunapruk ${ }^{1,4-6}$ \\ 'School of Pharmacy, Monash \\ University Malaysia, Selangor, \\ ${ }^{2}$ Department of Psychiatry and Mental \\ Health, Hospital Kuala Lumpur, \\ Kuala Lumpur, Malaysia; ${ }^{3}$ Faculty \\ of Pharmacy, Silpakorn University, \\ Nakhon Pathom, ${ }^{4}$ Center of \\ Pharmaceutical Outcomes Research \\ (CPOR), Department of Pharmacy \\ Practice, Faculty of Pharmaceutical \\ Sciences, Naresuan University, \\ Phitsanulok, Thailand; ${ }^{5}$ School of \\ Pharmacy, University of Wisconsin, \\ Madison, WI, USA; ${ }^{6} \mathrm{Health}$ and \\ Well-being Cluster, Global Asia in \\ the 2 Ist Century (GA2I) Platform, \\ Monash University Malaysia, \\ Selangor, Malaysia
}

Correspondence: Nathorn

Chaiyakunapruk

School of Pharmacy, Monash University

Malaysia, Jalan Lagoon Selatan, 47500

Bandar Sunway, Selangor Darul Ehsan,

Malaysia

Email nathorn.chaiyakunapruk@monash. edu
Introduction: Schizophrenia (SCZ) is a highly debilitating disease despite its low prevalence. The economic burden associated with SCZ is substantial and mainly attributed to productivity loss. To improve the understanding of economic burden of SCZ in the low- and middle-income country regions, we aimed to determine the economic burden of SCZ in Malaysia.

Methods: A retrospective study was conducted using a prevalence-based approach from a societal perspective in Malaysia with a 1 year period from 2013. We used micro-costing technique with bottom-up method and included direct medical cost, direct non-medical cost, and indirect cost. The main data source was medical chart review which was conducted in Hospital Kuala Lumpur (HKL). The medical charts were identified electronically by matching the unique patient's identification number registered under the National Mental Health Schizophrenia Registry and the list of patients in HKL in 2013. Other data sources were government documents, literatures, and local websites. To ensure robustness of result, probabilistic sensitivity analysis was conducted. Results: The total estimated number of treated SCZ cases in Malaysia in 2015 was 15,104 with the total economic burden of USD 100 million (M) which was equivalent to $0.04 \%$ of the national gross domestic product. On average, the mean cost per patient was USD 6,594. Of the total economic burden of SCZ, 72\% was attributed to indirect cost, costing at USD 72M, followed by direct medical cost (26\%), costing at USD 26M, and direct non-medical cost (2\%), costing at USD 1.7M.

Conclusion: This study highlights the magnitude of economic burden of SCZ and informs the policy-makers that there is an inadequate support for SCZ patients. More resources should be allocated to improve the condition of SCZ patients and to reduce the economic burden.

Keywords: economic burden, schizophrenia, Malaysia, cost of illness, lower-income countries, middle-income countries, societal perspective

\section{Introduction}

Schizophrenia (SCZ) is a chronic mental health disease characterized by delusions, hallucinations, and other symptoms which impair social and occupational functions. ${ }^{1}$ It has a low prevalence with a median period prevalence of $3.3 / 1,000$ persons. $^{2}$ However, it is a highly debilitating disease and ranked as the 11th leading cause of disability globally in $2013 .{ }^{3}$

The annual global economic burden associated with $\mathrm{SCZ}$ was estimated to range from USD 94 million (M) (Puerto Rico) to USD 102 billion (USA). ${ }^{4}$ Studies that compared the economic burden of SCZ to the gross domestic product (GDP) reported the cost to range from $0.02 \%$ (in the UK) to $1.65 \%$ (in Sweden) of GDP. ${ }^{4}$ The cost was mainly attributed to indirect cost incorporating loss of productivity and informal care cost, while the wide range of estimated cost was due to the difference in health care system, pattern of resource utilization, scope of cost components, diversity of the sampled populations, and data sources used. ${ }^{4}$

The economic burden study is essential as it enables understanding of the economic consequences associated with the disease. ${ }^{5}$ The majority of the economic burden studies 
of SCZ were conducted in high-income countries (HICs). ${ }^{4}$ In lower- and middle-income countries (LMICs), it is also important to understand the economic burden associated with this highly debilitating yet unrecognized disease in the region. Malaysia is one of the upper-middle-income countries ${ }^{6}$ with the lack of economic burden study of SCZ. To improve the understanding of economic burden of SCZ in the uppermiddle-income region, we aimed to determine the economic burden of SCZ in Malaysia from a societal perspective.

\section{Methods}

\section{General description}

We conducted a retrospective study using a prevalence-based approach from a societal perspective to assess the economic burden of SCZ in Malaysia. The study period was 1 year, from the first encounter of SCZ of each patient in 2013 (ie, any day from January 1, 2013 to December 31, 2013) as this was the most recent year with available data. We used micro-costing technique with bottom-up method, that is, the economic burden was calculated by the multiplication of the average cost per patient and the prevalence of SCZ. ${ }^{5}$ The costs included in the study were categorized into three main components of direct medical cost, direct non-medical cost, and indirect cost.

The economic burden was expressed as the total annual cost of SCZ and the mean cost per SCZ patient in MYR 2015 and USD 2015 (1 USD = MYR 4.30). ${ }^{7}$ If the cost available in the data source was before 2015, it was converted to 2015 using an average consumer price index. ${ }^{8}$

This study was approved by Medical Research Ethics Committee, Malaysia, and Monash University Human Research Ethics Committee, Australia. A waiver of patient consent was obtained as the patients' data used in the study were existing data recorded during the course of clinical care and they were de-identified.

\section{Prevalence of SCZ in Malaysia}

In Malaysia, SCZ patients generally receive health care through outpatient department (OPD), emergency department (ED), inpatient department (IPD), or/and community psychiatric services (CPSs) (where health care professionals deliver care at the house of patients) provided by general hospitals, university hospitals, or long-stay hospitals (for patients who require longer hospital stay).

To estimate the prevalence of SCZ in Malaysia in 2015, we included the total number of SCZ patients receiving psychiatric health care services in general hospitals, university hospitals, and long-stay hospitals. The data sources used were the psychiatric services report of Ministry of Health $(\mathrm{MOH})$ Malaysia (unpublished) for psychiatric patients in general and long-stay hospitals and the annual reports of university hospitals ${ }^{9-11}$ for psychiatric patients in university hospitals. As the only datum available in these data sources was the number of all psychiatric conditions, we used medical chart review and the annual report of one of the long-stay hospitals (Hospital Bahagia Ulu Kinta; unpublished) to obtain the percentage of SCZ patients in all psychiatric patients to estimate the number of SCZ patients in the hospitals.

\section{Medical chart review}

In fact, the primary data source in this study was medical chart review which was conducted in Hospital Kuala Lumpur (HKL), the largest general hospital under the $\mathrm{MOH}$ in Malaysia. ${ }^{12}$ The medical charts of SCZ patients in HKL were identified electronically through the matching of the unique patient's identification number in the National Mental Health Schizophrenia Registry and the list of patients who received health care services in HKL in 2013. The shortlisted patients were then checked if they fulfilled the inclusion criteria of 1) being adults aged at least 18 years and 2) diagnosed with SCZ based on Diagnostic and Statistical Manual of Mental Disorders, fifth edition (DSM-5). ${ }^{1}$ To ensure no missing data, medical charts with damaged conditions, for example, torn pages, were excluded.

The included medical charts were reviewed longitudinally for a year period from patient's first receiving of health care service in 2013. The data from medical chart review used in the analysis included 1) the utilization of medical services including pharmacological therapy (all prescribed medications) and non-pharmacological therapy (electroconvulsive therapies and laboratory tests), 2) the documented information on employment, and 3 ) the documented additional care receiving from hiring nurse, nursing home, or family and friends.

We calculated the sample size required to be 384 subjects based on a $10 \%$ of relative error and the standard deviation of cost of MYR $1,800^{13}$ with type 1 error of $1.96 .{ }^{14}$ We identified a total of $479 \mathrm{SCZ}$ patients who received health care in HKL based on the matching of patient's identification number, and only 422 met the inclusion criteria for analysis. Fifty-seven cases were excluded because there were no encounters of SCZ in $2013(n=36)$. The flowchart of the patient selection was shown in Figure S1.

\section{Direct medical cost}

The total direct medical cost was the sum of cost for OPD, ED, IPD, and CPS in all hospitals, obtained by multiplying 
the number of patients utilizing the service and the cost per patient. The cost per patient for OPD, ED, IPD, and CPS was calculated using the patient's medical services utilization data collected through medical chart review multiplied with the unit cost.

The data sources used included 1) psychiatric services report of $\mathrm{MOH}$ Malaysia (unpublished) for the number of patients utilizing each service, 2) $\mathrm{MOH}$ Malaysia Medical Services Charges ${ }^{15}$ (assuming it reflected the actual costs and incorporated all the administrative costs, professional fees, and all relevant costs incurred to provide the medical services) for unit cost of medical services provided in the hospitals; if not available, estimated by the calculation of private hospital charges ${ }^{16}$ minus the average difference of private hospital ${ }^{16}$ and the MOH charges ${ }^{15}$ and 3) HKL's medication price list in 2013 (unpublished) for medication cost.

\section{Direct non-medical cost}

The total direct non-medical cost was obtained through adding up the cost of patients' transportation to obtain medical services, the cost of nurse hiring and nursing home stay, where the number of patients (by multiplying the percentage of SCZ patients obtained from the medical chart review with the total number of SCZ patients) was multiplied with unit cost.

The data sources used included 1) unit cost per kilometer provided by Ministry of Finance Malaysia ${ }^{17}$ and the average distance travelled from patients' home to hospitals and clinics obtained from the government report ${ }^{18}$ for transportation's unit cost, 2) the annual salary of nurse from a local website ${ }^{19}$ for the unit cost of nurse hiring, and 3) nursing home stay charges estimated from local literature $^{20}$ for unit cost of nursing home stay.

\section{Indirect cost}

The total indirect non-medical cost was obtained through adding up the productivity loss for 1) absenteeism (leave from work) and presenteeism (reduction of work performance) for patients who worked, 2) unemployment, 3) informal care, that is, family and friends of SCZ patients for giving care to them, and 4) mortality using human capital method, multiplying the number of patients affected (obtained from multiplying the percentage of SCZ patients obtained from the medical chart review with the total number of SCZ patients) and the cost per patient. The cost of absenteeism per patient was estimated using 35 hours being absent from work $^{21}$ over the total number of working (176) hours. The cost of presenteeism per patient was estimated to be $10 \%{ }^{21}$ of the average annual income..$^{22}$ The cost of unemployment per patient was estimated based on those who intended to work among SCZ patients. This was calculated using the difference of employment rate between general population ${ }^{23}$ and SCZ patients (obtained through the medical chart review) by considering labor participation rate, ${ }^{23}$ subsequently multiplied with the average annual income. ${ }^{22}$ The cost of informal care per patient was estimated using 40 hours (spent to assist SCZ patients) ${ }^{21}$ over the total number of working (176) hours multiplied with the average annual income. ${ }^{22}$ The cost of mortality per patient was estimated using productivity loss from the age of premature death for mental health patients (ie, 38$)^{24}$ multiplied with the difference between mortality rate for SCZ patients (obtained from SCZ 1-year outcome report; unpublished) and general population; ${ }^{25}$ productivity loss was the sum of the multiplication of age-specific average income ${ }^{22}$ and labor participation rate. ${ }^{23}$ The details of input parameters were shown in Table S1.

\section{Total economic burden of SCZ}

The total economic burden of SCZ was the sum of total direct medical cost, total direct non-medical cost, and total indirect cost.

\section{Sensitivity analysis}

To ensure the robustness of results, probabilistic sensitivity analysis was conducted to examine the effect of uncertainty on all input parameters using a Monte Carlo simulation. This analysis was conducted using Microsoft Excel ${ }^{\circledR}$ (Microsoft Corporation, Redmond, WA, USA).

The input parameters were assigned with the probability distribution with this method: 1) the percentage of patients, in which their values ranged from 0 to 1 , was specified with a beta distribution and 2) the length of stay and cost with a positively skewed distribution and values above 0 were specified with a gamma distribution. ${ }^{26}$

We performed 1,000 iterations to allow multiple recalculations using different values generated from the uncertainty distributions assigned to the input parameters. In turn, the costs were presented in 95\% credible interval $(\mathrm{CrI})$.

\section{Results}

\section{Total number of treated SCZ patients in Malaysia}

In HKL, there were a total of 26,392 mental health patients in 2015 (psychiatric services report of $\mathrm{MOH}$; unpublished). Using the number of identified SCZ cases which were included for medical chart review (MCR) in HKL (ie, 422), 
it can be estimated that the proportion of SCZ patients to the total mental health patients was 0.02 (422/26,392). For longstay hospitals, the number of SCZ patients was estimated using the proportion of SCZ patient to the total mental health patients of 0.83 (Hospital Bahagia Ulu Kinta's annual report). Based on the adjustment of the proportion of SCZ patients, the total number of treated SCZ patients in Malaysia in 2015 was 15,104 . The details of the number of treated SCZ patients were shown in Table 1.

\section{Subject characteristics}

Of the 422 patients included for MCR, the mean age was 37 years with a standard deviation of 11 years. The ratio of male to female patients was $2: 1$, where $67 \%$ (284/422) of the patients were male. The majority $(417 / 422,99 \%)$ of patients were Malaysian with more than half $(218 / 422,52 \%)$ being Malay, followed by Chinese (136/422, 33\%), Indian (55/422, $13 \%)$, and other races $(8 / 422,2 \%)$.

Apart from SCZ, only 9\% (38/422) of the patients had other mental diseases, and less than a quarter of patients $(87 / 422,21 \%)$ had other diseases. In the last 5 years, the majority $(352 / 422,83 \%)$ of the patients had no illicit substance abuse history, while $11 \%(45 / 422)$ of the patients had single illicit substance abuse history and 6\% (25/422) had multiple (ie, $>1$ ) illicit substance abuse history. A small number of patients had suicidal ideation $(6 / 422,1 \%)$ and suicidal attempt $(12 / 422,3 \%)$ in the last 5 years. The details on subject characteristics were summarized in Table 2.

\section{Cost estimates}

\section{Total direct medical cost}

The total direct medical cost was MYR $111 \mathrm{M}$ or USD 26M. The majority ( $83 \%$ ) of the cost came from long-stay hospitals (MYR 92M or USD 21M), compared to general hospitals and university hospitals (17\%) (MYR 19M or USD $5 \mathrm{M})$. The high cost of long-stay hospitals was mainly (96\%) contributed by IPD as a high proportion of patients (Table 1) staying in the hospitals for a prolonged period of an average of 139 days annually. Whereas in general and university hospitals, majority (71\%) of the cost came from OPD as a high proportion of patients utilizing the OPD service with an average of 13 visits annually, followed by a $20 \%$ of cost from CPSs which was utilized by a substantial number of SCZ patients with an average of 7 visits annually. The annual average frequency of health care utilization per patient was summarized in Table 3.

\section{Total direct non-medical cost}

The total direct non-medical cost was MYR 7M or USD $1.7 \mathrm{M}$. The majority $(68 \%)$ of the cost was attributed to nursing home stay (MYR 5M or USD 1M) compared to the cost of nurse hiring service ( $9 \%)$. This was due to more patients $(5 \%)$ utilizing the nursing home stay service compared to $<1 \%$ of the patients which utilized nurse hiring service at a higher cost per patient cost (Table S2). The remaining $23 \%$ of the direct non-medical cost came from patient's transportation cost to obtain medical services.

\section{Total indirect cost}

The total indirect cost or productivity loss was MYR 310M or USD $72 \mathrm{M}$. More than half $(55 \%)$ of the productivity loss was caused by unemployment. Compared to the general population, the unemployment rate for SCZ patients (obtained from medical chart review) was as high as 55\%, compared to $3 \%$ for the general population. ${ }^{23}$ The time spent by SCZ patient's family and friends also contributed a substantial $(27 \%)$ of productivity loss as $87 \%$ of SCZ patients was found (from the medical chart review) to require care from them. SCZ also cost a $10 \%$ and $5 \%$ of productivity loss for absenteeism (ie, absence from work) and presenteeism (ie, reduction in performance/productivity of work), respectively, for $36 \%$ of SCZ patients who worked. Although the productivity loss per patient caused by mortality associated with SCZ was substantial (MYR 0.1M or USD 0.03M), only

Table I Number of treated schizophrenia patients in Malaysia in 2015

\begin{tabular}{|c|c|c|c|c|c|}
\hline \multirow{2}{*}{$\begin{array}{l}\text { Hospital, total number of } \\
\text { hospitals in Malaysia }\end{array}$} & \multicolumn{4}{|c|}{ Number of treated schizophrenia patients } & \multirow[t]{2}{*}{ Data source(s) } \\
\hline & OPD & IPD & CPS & Total & \\
\hline All general hospitals, 46 & 7,121 & 293 & $\mathrm{I}, 543$ & $7,4 \mid 4$ & $\begin{array}{l}\text { Psychiatric services report of } \\
\text { Ministry of Health (unpublished) }\end{array}$ \\
\hline All long-stay hospitals, 4 & 1,213 & 3,392 & 36,419 & 4,605 & \\
\hline All university hospitals, $3 *$ & 781 & 16 & 47 & 797 & $9-11$ \\
\hline All hospitals & & & & 15,104 & \\
\hline
\end{tabular}

Note: *Only I out of the 3 university hospitals provides CPS.

Abbreviations: OPD, outpatient department; IPD, inpatient department; CPS, community psychiatric service. 
Table 2 Subject characteristics of schizophrenia patients in Hospital Kuala Lumpur

\begin{tabular}{ll}
\hline Subject characteristics & Results, $\mathbf{n}(\%)$ \\
\hline Age (years), mean \pm standard deviation & $37 \pm$ I I \\
Male:female & $2: 1$ \\
Race & \\
$\quad$ Malay & $218(52)$ \\
$\quad$ Chinese & $136(33)$ \\
Indian & $55(13)$ \\
Others & $8(2)$ \\
With other mental diseases & $38(9)$ \\
With non-mental diseases & $87(21)$ \\
Illicit substance abuse (in the last 5 years) & \\
Single & $45(11)$ \\
Multiple & $25(6)$ \\
No & $352(83)$ \\
Suicidal history (in the last 5 years) & \\
Ideation & $6(1)$ \\
Attempt & $12(3)$ \\
\hline
\end{tabular}

a very small number $(<1 \%)$ of SCZ patients was estimated to be affected.

The input parameters used to calculate the cost estimated were summarized in Table S1 while the details on the utilization rate and the proportion of patients affected for each cost component were summarized in Table S3.

\section{Total economic burden of SCZ}

Overall, the total economic burden of SCZ in Malaysia in 2015 was estimated to be MYR 428M or USD $100 \mathrm{M}$. Compared to the national GDP of 2015, which was MYR 1,063 billion or USD 247 billion, ${ }^{25}$ the total economic burden of SCZ was $0.04 \%$ of the national GDP. Averaging the total cost to the total number of SCZ patients, the mean cost per patient was MYR 28,353 or USD 6,594.

Of the total economic burden of SCZ, $72 \%$ was attributed to indirect cost, followed by direct medical cost (26\%)

Table 3 Average frequency of health care utilization per patient* per year

\begin{tabular}{|c|c|c|}
\hline Category & Details & Data source \\
\hline Outpatient department & 13 visits & MCR \\
\hline Inpatient department & I visit & MCR \\
\hline Emergency department & I visit & MCR \\
\hline Community psychiatric services & 7 visits & MCR \\
\hline $\begin{array}{l}\text { Length of stay in general and } \\
\text { university hospitals }\end{array}$ & 26 days & MCR \\
\hline $\begin{array}{l}\text { Length of stay in long-stay } \\
\text { hospitals }\end{array}$ & 139 days & $\begin{array}{l}\text { Psychiatric services } \\
\text { report of Ministry of } \\
\text { Health (unpublished) }\end{array}$ \\
\hline
\end{tabular}

Note: *Per patient who utilized the specific services.

Abbreviation: MCR, medical chart review.
Table 4 Economic burden of schizophrenia in Malaysia

\begin{tabular}{lll}
\hline Category & $\begin{array}{l}\text { USD 20 I5 } \\
\text { million, \% }\end{array}$ & $\begin{array}{l}\text { Proportion to } \\
\text { total cost (\%) }\end{array}$ \\
\hline Total direct medical costs & 26 & 26 \\
General hospitals & 4 & \\
Outpatient department & 3,70 & \\
Inpatient department & $0.3,8$ & \\
Emergency department & $0.03,<\mathrm{I}$ & \\
Community psychiatric services & $0.9,22$ & \\
University hospitals & 0.4 & \\
Outpatient department & $0.3,87$ & \\
Inpatient department & $0.02,5$ & \\
Emergency department & $0.003,<1$ & \\
Community psychiatric services & $0.03,7$ & \\
Long-stay hospitals & 21 & \\
Outpatient department & $0.5,2$ & \\
Inpatient department & 20,96 & \\
Emergency department & $0.005,<1$ & \\
Community psychiatric services & $0.4,2$ & \\
Total direct non-medical costs & 1.7 & \\
Transportation & $0.4,23$ \\
Hiring nurse & $0.2,10$ \\
Nursing home stay & $1.1,68$ \\
Total indirect costs & 72 & 72 \\
Absenteeism & 7,10 & \\
Presenteeism & 4,5 & \\
Unemployment & 40,55 \\
Mortality & 2,3 & \\
Informal care & 19,27 & \\
Total economic burden & 100 & \\
\hline
\end{tabular}

and direct non-medical cost (2\%). The economic burden of SCZ was summarized in Table 4.

\section{Sensitivity analysis}

Probabilistic sensitivity analysis showed that the total economic burden of SCZ was MYR 418M (95\% CrI: 402M, $435 \mathrm{M})$ or USD $97 \mathrm{M}(93 \mathrm{M}, 101 \mathrm{M})$. Consistent to our basecase analysis, the largest proportion of the cost was from indirect cost (72\%) with MYR 300M (284M, 316M) or USD $70 \mathrm{M}(66 \mathrm{M}, 73 \mathrm{M})$, followed by $27 \%$ from direct medical cost with MYR 111M (106M, 116M) or USD 26M (25M, 27M) and $2 \%$ from total direct non-medical cost with MYR 7M $(5 \mathrm{M}, 10 \mathrm{M})$ or USD $1.7 \mathrm{M}(1.2 \mathrm{M}, 2.3 \mathrm{M})$.

\section{Discussion}

To the best of our knowledge, this is the first study investigating the economic burden of SCZ in Malaysia. Our study estimated that SCZ costs MYR 428M or USD 100M, equivalent to $0.04 \%$ of the national GDP, to the society of Malaysia in 2015. The largest proportion of the cost of SCZ came from the productivity loss mainly associated with unemployment and informal care provided by patients' family and friends. 
Compared to the global economic burden of SCZ, where most of the studies were conducted in HICs, our result falls within the global estimate of USD 94M to USD 102 billion or $0.02 \%$ to $1.65 \%$ of total cost to the national GDPs. ${ }^{4}$ Therefore, our study reiterates that $\mathrm{SCZ}$ causes a substantial economic burden to the society in both HICs and LMICs.

Including our study, the majority of the studies found that the main proportion of economic burden of SCZ was the indirect cost or productivity loss. ${ }^{4}$ It shows that $\mathrm{SCZ}$ is highly debilitating impairing the ability of SCZ patients and their family and friends to work which causes substantial loss to the society. Therefore, there is an imperative need to provide adequate support including health care services for SCZ patients to improve the conditions of SCZ patients and to reduce the associated productivity loss in the long-run.

Our findings showed that long-stay hospital services contributed to the largest proportion of direct medical costs, consistent with what have been reported in other studies in the $\mathrm{USA}^{27}$ and the UK. ${ }^{28}$ One of the reasons which has caused a worsened condition of SCZ is the delay in seeking treatment. ${ }^{29}$ In Malaysia, it was reported that on average there was a delay of $>2$ years before SCZ patients sought for health care. ${ }^{29}$ Therefore, a concerted effort should be implemented to improve the treatment-seeking behavior for $\mathrm{SCZ}$ patients at an early stage of the disease.

The strength of our study was that real patient data were used to estimate the input parameters including 1) the health care utilization rate for health care services, 2) cost of medical services per patient, and 3) the prevalence of SCZ cases in Malaysia to provide a more realistic estimate. In addition, through the employment of bottom-up or person-based approach, we were also able to capture data specific for SCZ patients including 1) the utilization rates and frequency of use for health care services and 2) the proportion of SCZ patients affected for each cost component which enabled more future studies targeted to improve the condition of SCZ patients.

Despite our endeavor to produce the accurate estimate in this study, the actual economic burden of SCZ is likely to be higher than our estimate due to the lower estimated SCZ prevalence compared to the global prevalence. ${ }^{2}$ This is because our analysis includes only patients who have health care access and have been diagnosed with SCZ. In addition, by using the retrospective approach for this study, the number of patients requiring formal or informal care might not be fully captured by the documentation in the medical charts. In turn, both direct and indirect costs estimated were likely to be underestimated. Despite the limited data, we believed we have best utilized the available data sources to produce the estimate. Nevertheless, the results in our study should be interpreted with caution. More local study should be conducted to provide a better estimation of the SCZ prevalence in Malaysia to improve SCZ-related studies in the future.

\section{Conclusion}

This study highlights the magnitude of economic burden caused by the highly debilitating yet unrecognized disease. It informs the policy-makers that there is an inadequate support for SCZ patients. More resources should be allocated for SCZ patients to improve the condition of SCZ patients through a multidisciplinary approach including providing adequate health care services, public health education, and other measures. Recognizing the highly costly nature of the disease would be one of the most crucial steps to ensure that SCZ patients receive adequate care and to reduce the overall economic burden caused by the disease to the society.

\section{Acknowledgments}

We thank Dr S Kasthoori Supramaniam and Dr Shahril Azlan Abdul Aziz from HKL for their help in facilitating the process of medical chart review. This study was funded by Johnson \& Johnson Sdn Bhd, Malaysia. The study abstract was presented in the International Society of Pharmacoeconomics and Outcomes Research (ISPOR) 7th Asia-Pacific Conference and published in Value in Health.

\section{Author contributions}

All authors made substantial contributions to conception and design, acquisition of data, or analysis and interpretation of data; took part in drafting the article or revising it critically for important intellectual content; gave final approval of the version to be published; and agree to be accountable for all aspects of the work.

\section{Disclosure}

The authors report no conflicts of interest in this work.

\section{References}

1. American Psychiatric Association. Diagnostic and Statistical Manual of Mental Disorders (DSM-5®). Arlington, VA: American Psychiatric Publication; 2013.

2. Saha S, Chant D, Welham J, McGrath J. A systematic review of the prevalence of schizophrenia. PLoS Med. 2005;2(5):e141.

3. Vos T, Barber RM, Bell B, et al. Global, regional, and national incidence, prevalence, and years lived with disability for 301 acute and chronic diseases and injuries in 188 countries, 1990-2013: a systematic analysis for the Global Burden of Disease Study 2013. Lancet. 2015; 386(9995): 743-800.

4. Chong HY, Teoh SL, Wu DB-C, Kotirum S, Chiou C-F, ChaiyakunaprukN. Global economic burden of schizophrenia: a systematic review. Neuropsychiatr Dis Treat. 2016;12:357. 
5. Segel JE. Cost-of-illness studies - a primer. RTI-UNC Center of Excellence in Health Promotion Economics. 2006:1-39.

6. The World Bank. Country and Lending Groups. Data. Available from: http://data.worldbank.org/about/country-and-lending-groups\#Upper_ middle_income. Accessed June 7, 2016.

7. XE Currency Converter. Current and Historical Rate Tables. Available from: http://www.xe.com/currencytables/?from=MYR\&date $=20$ 15-12-31. Accessed April 21, 2016.

8. International Monetary Fund. World Economic Outlook Database. Available from: http://www.imf.org/external/pubs/ft/weo/2016/01/ weodata/weorept.aspx ?sy $=2013 \&$ ey $=2015 \& \mathrm{scsm}=1 \& \mathrm{ssd}=1 \&$ sort $=$ cou ntry \&ds $=. \& b r=1 \& p r 1 . x=45 \& p r 1 . y=12 \& c=548 \& s=$ PCPI\&grp $=0 \& a=$. Accessed May 11, 2016

9. Hospital Canselor Tuanku Muhriz. Hospital Statistics. Malaysia: Hospital Canselor Tuanku Muhriz; 2015.

10. Hospital Universiti Sains Malaysia. Hospital Universiti Sains Malaysia Statistics. Malaysia: Hospital Universiti Sains Malaysia; 2014.

11. University Malaya Medical Centre. Annual Report. Malaysia: University Malaya Medical Centre; 2013.

12. Hospital Kuala Lumpur. Introduction. Available from: http://www.hkl. gov.my/content/about1.htm. Accessed January 3, 2017.

13. Mohd Nordin NA, Syed Junid SA, Aziz NA, Muhammad Nur A, Sulong S. Direct medical cost of stroke: findings from a tertiary hospital in Malaysia. Med J Malaysia. 2012;67(5):473-477.

14. Rosner B. Fundamentals of Biostatistics. 7th ed. Boston, MA: Brooks/ Cole, Cengage Learning; 2011.

15. Attorney General's Chambers Malaysia. Fees (Medical) (Cost of Services) Order 2014. Federal Government Gazette; 2014.

16. Attorney General's Chambers Malaysia. Private Healthcare Facilities and Services (Private Hospitals and Other Private Healthcare Facilities) (Amendment) Order 2013. Federal Government Gazette; 2013.

17. Elamin EI, Ibrahim MIM, Sulaiman SAS, Muttalif AR. Cost of illness of tuberculosis in Penang, Malaysia. Pharm World Sci. 2008;30(3): $281-286$
18. Ministry of Health Malaysia. National Health and Morbidity Survey (NHMS) 2015. Institute for Public Health; 2015.

19. Pay Scale. Salary Data and Career Research Center (Malaysia). Available from: http://www.payscale.com/research/MY/Country=Malaysia/ Salary. Accessed December 2, 2015.

20. Sim M. Cost of taking care of the elderly; 2013. Available from: http:// www.freemalaysiatoday.com/category/leisure/2013/09/25/cost-oftaking-care-of-the-elderly/. Accessed December 2, 2015.

21. Phanthunane P, Whiteford H, Vos T, Bertram M. Economic burden of schizophrenia: empirical analyses from a survey in Thailand. $J$ Ment Health Policy Econ. 2012;15(1):25-32.

22. Department of Statistics Malaysia. Salaries and Wages Survey Report Malaysia 2014. Department of Statistics Malaysia Official Portal; 2014.

23. Department of Statistics Malaysia. Labour Force Survey Report Department of Statistics Malaysia Official Portal; 2015.

24. NSRM Ministry of Health Malaysia. National Suicide Registry Malaysia (NSRM) Annual Report for 2009. Kuala Lumpur; 2011.

25. Department of Statistics Malaysia. Gross domestic product. Department of Statistics Malaysia Official Portal; 2015.

26. Supon Limwattananon M. Handling uncertainty of the economic evaluation result: sensitivity analysis. $J$ Med Assoc Thai. 2008;91(2): S59-S65.

27. Wu EQ, Birnbaum HG, Shi L, et al. The economic burden of schizophrenia in the United States in 2002. J Clin Psychiatry. 2005;66(9): $1478-1129$.

28. Mangalore R, Knapp M. Cost of schizophrenia in England. $J$ Ment Health Policy Econ. 2007;10(1):23.

29. Aziz SA. The First Report of the National Mental Health Registry on Schizophrenia. Kuala Lumpur: National Mental Health Registry (NMHR); 2005. 


\section{Supplementary materials}

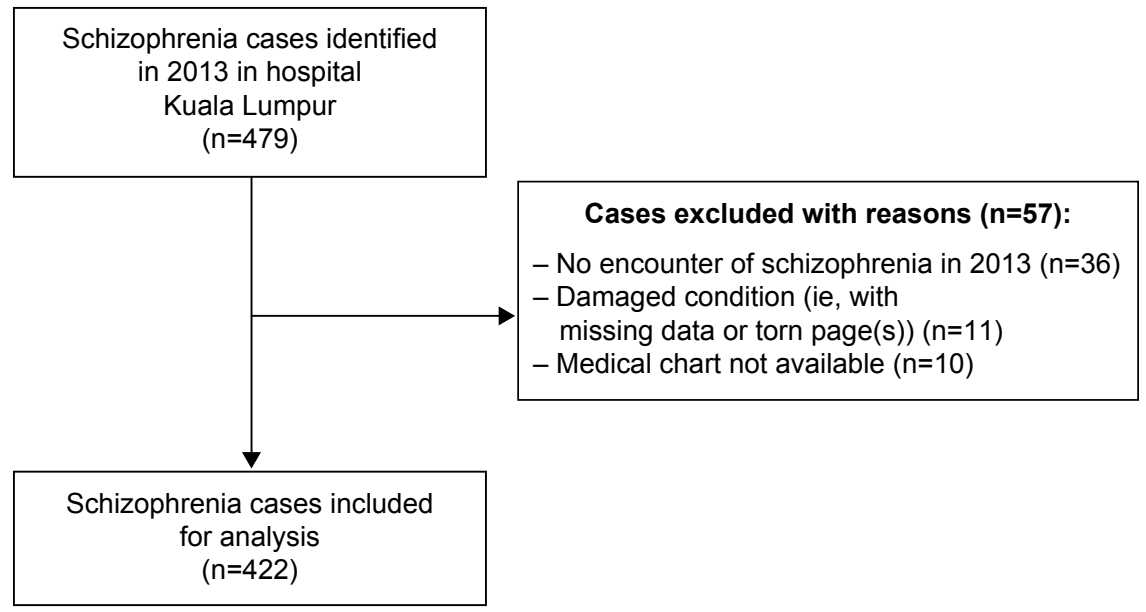

Figure SI Flowchart of subject selection in Hospital Kuala Lumpur.

Table SI Input parameters for cost per patient calculation

\begin{tabular}{|c|c|c|}
\hline Cost component & Detail & Data source \\
\hline \multicolumn{3}{|l|}{ Direct medical costs } \\
\hline Outpatient department (OPD) clinic charge, per visit (USD 2015) & 28 & I \\
\hline Inpatient department (IPD) ward stay charge, per day (USD 20I5) & 38 & I \\
\hline Emergency department charge, per visit (USD 2015) & 24 & I \\
\hline Community psychiatric services home visit charge, per round trip (USD 20I5) & 78 & $1-3$ \\
\hline Electroconvulsive therapy (for OPD and IPD), per therapy (USD 2015)^ & 72 & $\mathrm{I}, 4$ \\
\hline \multicolumn{3}{|l|}{ Direct non-medical costs } \\
\hline \multicolumn{3}{|l|}{ Transportation cost } \\
\hline Clinic, per round trip (USD 20I5) & 3 & 2,3 \\
\hline Hospital, per round trip (USD 20I5) & 7 & 2,3 \\
\hline \multicolumn{3}{|l|}{ Indirect costs } \\
\hline Number of absent hours from work & 35 & 5 \\
\hline Reduction of work performance & $10 \%$ & 5 \\
\hline Unemployment rate for general population & $3 \%$ & 6 \\
\hline Unemployment rate for SCZ patients & $55 \%$ & MCR \\
\hline Average annual income per patient for adults (USD 2015) & 6,482 & 6,7 \\
\hline Labor participation rate for general population & $77.4 \%$ & 6 \\
\hline Age of premature death for mental health patients & 38 & 8 \\
\hline Age-specific average annual income per patient from age 38 onwards (USD 2015) & $5,9|3-8,6| 1$ & 7 \\
\hline Age-specific labor participation rate from age 38 onwards & $39.3 \%-83.5 \%$ & 6 \\
\hline Mortality rate for SCZ patients & $0.5 \%$ & $\begin{array}{l}\text { SCZ I year outcome } \\
\text { report (unpublished) }\end{array}$ \\
\hline Mortality rate for general population & $0.001 \%$ & 9 \\
\hline Number of hours family and friends spent to assist SCZ patients & 40 & 5 \\
\hline
\end{tabular}

Notes: \#Including the transportation cost for a round trip from hospital to patient's home. 'Based on the calculation of USD 75 (charge in private sector) minus off USD 3 (the average difference between the charge of private sector and Ministry of Health medical services charges).

Abbreviations: MCR, medical chart review; SCZ, schizophrenia. 
Table S2 Annual cost per utilization for schizophrenia patients in 2015

\begin{tabular}{|c|c|c|}
\hline Category & $\begin{array}{l}\text { Average cost per } \\
\text { patient }{ }^{\pi}, \text { USD } 2015\end{array}$ & Data source \\
\hline \multicolumn{3}{|l|}{ Direct medical costs } \\
\hline Outpatient department & 406 & I,4,MCR \\
\hline $\begin{array}{l}\text { Inpatient department (general } \\
\text { and university hospitals) }\end{array}$ & 1,143 & I,4,MCR \\
\hline $\begin{array}{l}\text { Inpatient department } \\
\text { (long-stay hospitals) }\end{array}$ & 6,029 & \\
\hline Emergency department (ED) & 34 & I,MCR \\
\hline $\begin{array}{l}\text { Community psychiatric } \\
\text { services }\end{array}$ & 581 & I,MCR \\
\hline \multicolumn{3}{|l|}{ Direct non-medical costs } \\
\hline Transportation & 72 & 2,3,MCR \\
\hline Hiring nurse & 6,957 & 10 \\
\hline Nursing home stay & 2,351 & 11 \\
\hline \multicolumn{3}{|l|}{ Indirect costs } \\
\hline Absenteeism & 1,289 & 5,7 \\
\hline Presenteeism & 648 & 5,7 \\
\hline Unemployment & 6,482 & 7 \\
\hline Mortality & 30,019 & $6,7, M C R$ \\
\hline Informal care & $\mathrm{I}, 473$ & 5,7 \\
\hline \multicolumn{3}{|c|}{$\begin{array}{l}\text { Note: }{ }^{\top} \text { Average cost per patient who utilized the health care service or who was } \\
\text { affected for the cost component incorporating the average utilization per patient } \\
\text { per year. } \\
\text { Abbreviations: Crl, credible interval; MCR, medical chart review; MOH, Ministry } \\
\text { of Health. }\end{array}$} \\
\hline \multicolumn{3}{|c|}{$\begin{array}{l}\text { Table S3 The percentage of SCZ patients affected for each cost } \\
\text { component }\end{array}$} \\
\hline Cost components & & $\begin{array}{l}\text { Percentage of } \\
\text { SCZ patients }\end{array}$ \\
\hline \multicolumn{3}{|l|}{ Direct non-medical costs } \\
\hline Formal caregiver & & $0.2 \%$ \\
\hline Nursing home stay & & $5 \%$ \\
\hline \multicolumn{3}{|l|}{ Indirect costs } \\
\hline Absenteeism & & $36 \%$ \\
\hline Presenteeism & & $36 \%$ \\
\hline Unemployment rate & & $41 \%$ \\
\hline Informal care & & $87 \%$ \\
\hline Mortality & & $0.5 \%$ \\
\hline
\end{tabular}

Abbreviation: SCZ, schizophrenia.

\section{References}

1. Attorney General's Chambers Malaysia. Fees (Medical) (Cost of Services) Order 2014. Federal Government Gazette; 2014.

2. Elamin EI, Ibrahim MIM, Sulaiman SAS, Muttalif AR. Cost of illness of tuberculosis in Penang, Malaysia. Pharm World Sci. 2008;30(3): 281-286.

3. Ministry of Health Malaysia. National Health and Morbidity Survey (NHMS) 2015. Institute for Public Health; 2015.

4. Attorney General's Chambers Malaysia. Private Healthcare Facilities and Services (Private Hospitals and Other Private Healthcare Facilities) (Amendment) Order 2013. Federal Government Gazette; 2013.

5. Phanthunane P, Whiteford H, Vos T, Bertram M. Economic burden of schizophrenia: empirical analyses from a survey in Thailand. J Ment Health Policy Econ. 2012;15(1):25-32.

6. Department of Statistics Malaysia. Labour Force Survey Report. Department of Statistics Malaysia Official Portal; 2015.

7. Department of Statistics Malaysia. Salaries and Wages Survey Report Malaysia 2014. Department of Statistics Malaysia Official Portal; 2014.

8. NSRM Ministry of Health Malaysia. National Suicide Registry Malaysia (NSRM) Annual Report for 2009. Kuala Lumpur; 2011.

9. Department of Statistics Malaysia. Statistics on causes of death Malaysia (2010-2013). Department of Statistics Malaysia Official Portal; 2015.

10. Pay Scale. Salary Data and Career Research Center (Malaysia). Available from: http://www.payscale.com/research/MY/Country=Malaysia/ Salary. Accessed December 2, 2015.

11. Sim M. Cost of taking care of the elderly; 2013. Available from: http:// www.freemalaysiatoday.com/category/leisure/2013/09/25/cost-oftaking-care-of-the-elderly/. Accessed December 2, 2015.
Neuropsychiatric Disease and Treatment

\section{Publish your work in this journal}

Neuropsychiatric Disease and Treatment is an international, peerreviewed journal of clinical therapeutics and pharmacology focusing on concise rapid reporting of clinical or pre-clinical studies on a range of neuropsychiatric and neurological disorders. This journal is indexed on PubMed Central, the 'PsycINFO' database and CAS,

\section{Dovepress}

and is the official journal of The International Neuropsychiatric Association (INA). The manuscript management system is completely online and includes a very quick and fair peer-review system, which is all easy to use. Visit http://www.dovepress.com/testimonials.php to read real quotes from published authors. 